\title{
Evaluating Production Time Buffer for Precast Fabrication
}

\author{
Chien-Ho Ko ${ }^{1}$ and Yu-Chun Chen ${ }^{2}$ \\ ${ }^{1}$ Associate Professor, Department of Civil Engineering, National Pingtung University of Science and Technology, 1, \\ Shuefu Rd., Neipu, Pingtung 912, Taiwan. E-mail: ko@mail.npust.edu.tw (corresponding author). \\ ${ }^{2}$ MS, Department of Industrial Engineering and Technology Management, Da-Yeh University, Taiwan.
}

Project and Production Management

Received November 23, 2011; received revision December 28, 2011; accepted January 6, 2012

Available online April 5, 2012

\begin{abstract}
Precast fabricators strive for business success in delivering products on time. To achieve this goal, fabricators start manufacturing once they receive specific design information. However, this strategy induces wasteful inventory. The objective of this study is to develop a Time Buffer Evaluation Model (TBEM) to promptly deliver products and maintain a smaller inventory. This model consists of two stages. The first, by using fuzzy logic, considers factors that influence construction duration. The second stage evaluates a time buffer by considering the tardiness penalty and crashing costs. In this study, one real case is tested to demonstrate the applicability of the proposed method. The application results show that the developed TBEM can reduce the level of finished goods inventory without changing production resources.
\end{abstract}

Keywords: Fuzzy logic, precast, finished goods inventory, time buffer.

\section{Introduction}

In the precast industry, customer satisfaction is measured by on-time delivery. Late delivery can interrupt construction progress and thereby induce delays. Moreover, the consequences of late delivery include a penalty for contract infringement and deterioration of business reputation. To deliver products on time whenever customers need them, fabricators begin production upon receipt of specific design information. Unfortunately, since a building site may not have enough space to pre-store precast elements, customers often change delivery dates in accordance with construction progress. Consequently, numerous finished goods are stored in yards waiting to be delivered, a practice considered wasteful (Ohno, 1988).

Precast fabricators of engineered-to-order products face numerous challenges as they strive for business success. Among these, demand variability is arguably the biggest problem (Ko and Ballard, 2005; Ballard and Arbulu, 2004). One way to protect fabricators against the impact of demand variability is to finish production later relative to required delivery dates, thus reducing the risks of changes in delivery schedules and manufacturing a product that is either not yet needed or obsolete due design changes ( Ko and Ballard, 2004). However, how much later relative to the required delivery date fabricators can still deliver products on time but reduce the level of finished goods inventory is an important question.

According to the buffering law, systems with variability must be sheltered by some combination of inventory, capacity, and time (Hopp and Spearman, 2000).
The root method for solving problems induced by variability is to eliminate it. Thus, fabricators should constantly endeavor to reduce variability. Meanwhile, before variability has been totally eliminated, proper buffers are necessary to protect from the impact of changeability in demand. To deliver products on time (or Just-In-Time), a time buffer with a smaller inventory is needed. Otherwise, fabricators lose capacity due to vicious overtime cycles induced by variability.

The objective of this study is to develop a Time Buffer Evaluation Model (TBEM) to deliver products on time with a smaller inventory. To achieve this goal, a production strategy is proposed to reduce inventory and the risk of prematurely manufacturing products that is not yet needed. In the model, erection progress is first evaluated by using Fuzzy Logic (FL). An appropriate time buffer for delivering products on time with a smaller inventory is then analyzed by considering the cost of the tardiness penalty and crashing costs. Finally, the performance of the proposed method is validated by examining a real precast production project.

\section{Fuzzy Logic}

Uncertain and imprecise information is encountered while evaluating erection durations. In practice, factors influencing duration are difficult to quantify. Hence, the development of a mathematical model for duration estimation is complex and time-consuming. Fuzzy Logic (FL) has been proven to be an effective method for processing uncertain information in manufacturing systems (Chang, 1999; Wang et al., 1999; Adenso-Diaz et al., 2004; Singh et al., 2006). 
FL was first developed by Zadeh in the 1960s for representing uncertain and imprecise information (Zadeh, 1965). FL is broadly synonymous with fuzzy set theory, i.e., the theory of classes with unclear boundaries. More narrowly, FL is a system intended to serve as a means of approximate reasoning (Zadeh, 1994). Classical logic (two-valued logic) assumes that every proposition is either true or false, a basic assumption that has been questioned. Unlike classical logic, FL is viewed as an extension of multi-valued conventional logic.

FL simulates the high-level human decision-making process, which seeks to model imprecise modes of reasoning to make rational decisions in an environment of uncertainty and imprecision. Thus, FL provides approximate but effective descriptions for highly complex, ill-defined, or difficult-to-analyze mathematical systems (Zadeh, 2005). A general Fuzzy Logic System (FLS) contains four major components: a fuzzifier, an inference engine, a rule base, and a defuzzifier, as illustrated in Fig. 1 .

\section{Time Buffer Evaluation Model}

\subsection{Model Strategy}

To fulfill an erection schedule, precast fabricators start manufacturing as soon as they receive specific design information. However, this practice results in accumulated inventory, considered to be a major source of problems for manufacturers (Spearman, 2002). Change orders, categorized as demand variability, are among the largest sources of cost inflation on construction projects (Riley et al., 2005). Components fabricated before they are needed frequently succumb to change orders, such as modifications in size, quantity, and delivery date.

A strategy used to reduce inventory and protect fabricators against the impact of demand variability is to finish production later relative to required delivery dates, as illustrated in Fig. 2, where the adjusted production curve is "pulled" relatively close to the erection curve. To avoid out-of-capacity fabrication, the production curve is cushioned with a time buffer. For the progress $P$ in Fig. 4, an inventory level is decreased from $i$ to $i_{a}$. The time for finished goods inventory awaiting delivery is shortened from $t$ to a time buffer designated $b_{a}$. By adopting this strategy, both the inventory and the impact of demand variability can be reduced without increasing the production rate or the number of molds.

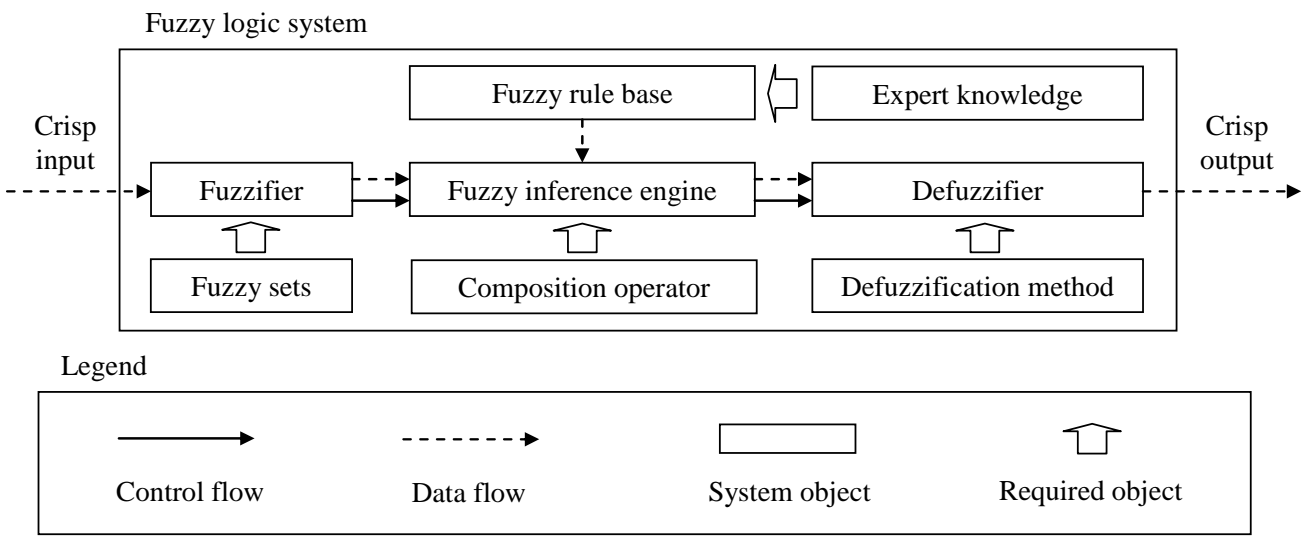

Fig. 1. Typical schema of a fuzzy logic system

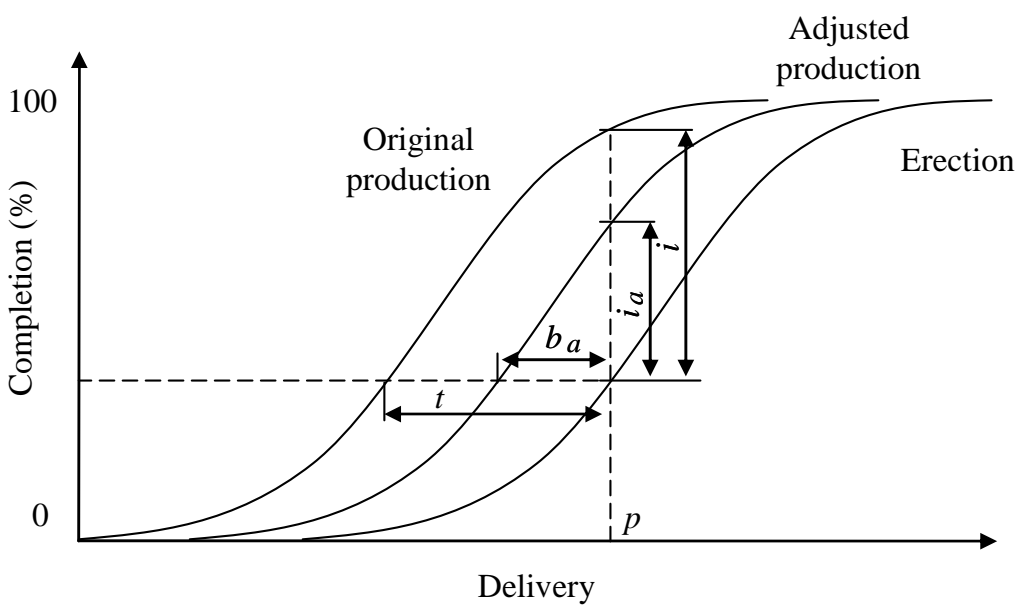

Fig. 2. Strategy of Time Buffer Evaluation Model 


\subsection{Model Structure}

The TBEM consists of two stages: erection duration inference and time buffer adjustment, as illustrated in Fig. 3. The duration of the construction is first evaluated by using fuzzy logic. Then, a time buffer is estimated by considering the tardiness penalty and crashing costs. Eventually, the production due dates for each story can be determined by progressing backward from the highest level, story by story, to the lowest level.

\subsection{Erection Duration Inference}

The erection progress is evaluated using FL, the process of which is developed by incorporating the following steps: 1) determine the inference method, 2) identify the input/output variables and their membership functions, 3) establish fuzzy rules, and 4) determine the defuzzification method.

1. Determine inference method:

Inference can be defined as a process of mapping from a given input to an output. The most commonly used fuzzy inference technique is the Mamdani Min-Max method (Mamdani and Assilian, 1975), as diagramed in Fig. 4. The Min operator performs fuzzy intersections (t-norms) which select the minimum membership for AND antecedents. The max operator functions as fuzzy unions (t-conorms) that select the maximum membership for $\mathrm{OR}$ antecedents in the fuzzy rules.

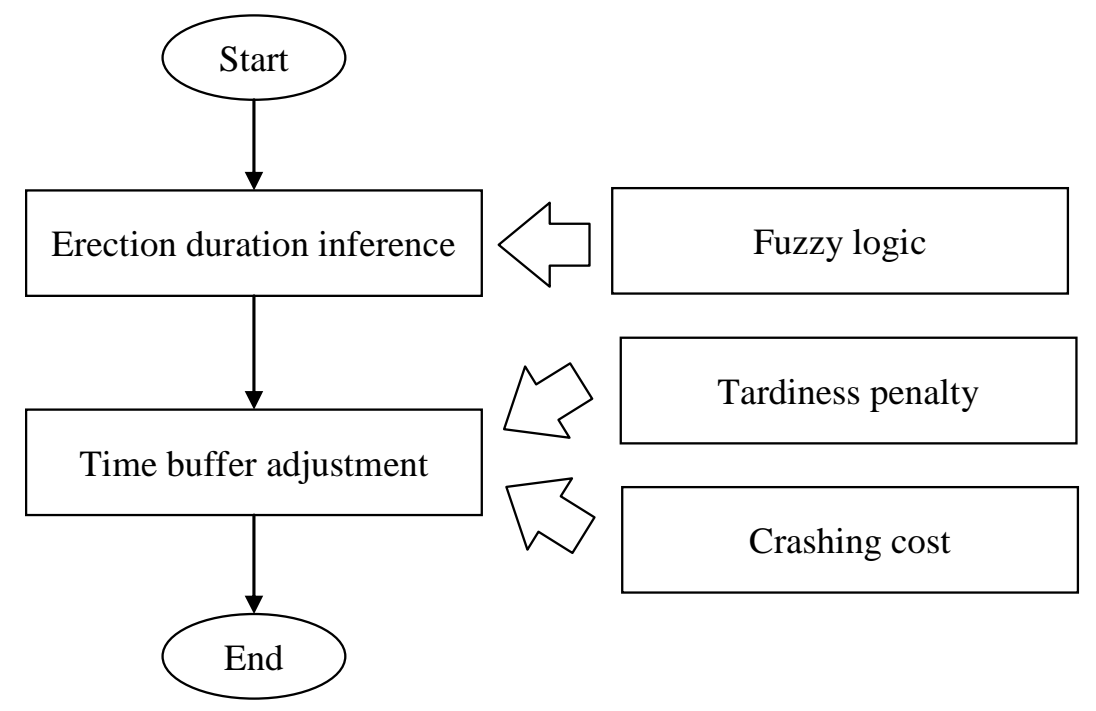

Fig. 3. Structure of Time Buffer Evaluation Model
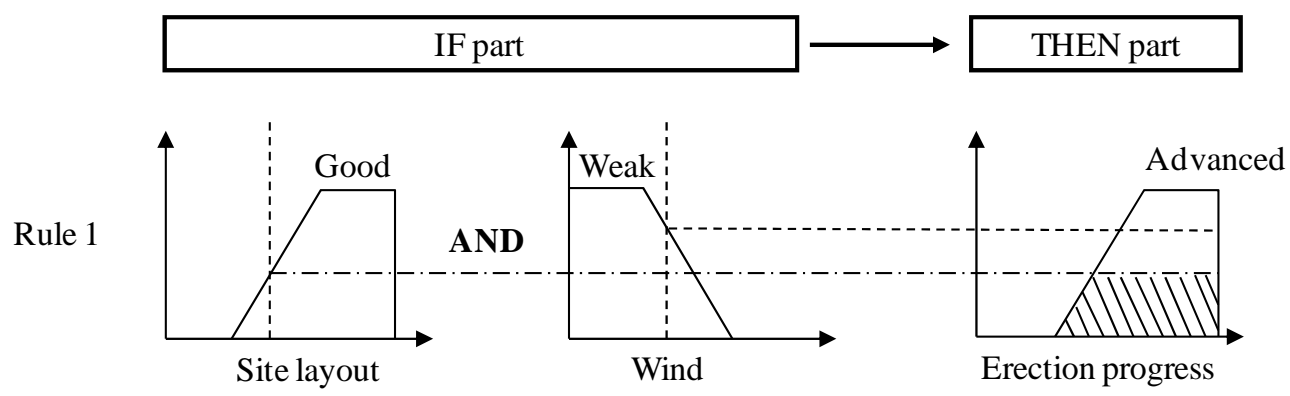

(a)

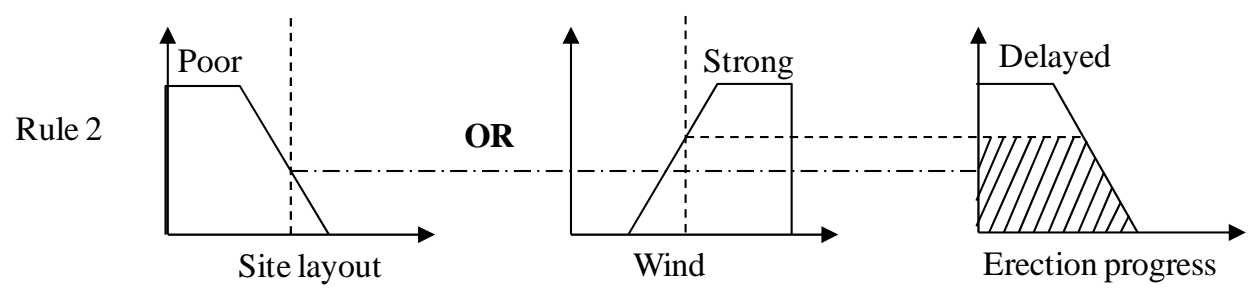

(b)

Fig. 4. Mamdani Min-Max method: (a) Min operator (b) Max operator 


\section{Identify variables and membership functions:}

The output of the inference constitutes the erection duration. Five input variables, namely lifting speed, site layout, wind speed, rainfall, and rainy days, influencing erection progress are identified through interviews with experts. Those interviewed in this study have more than 10 years' experience in precast construction. The membership functions of each input/output linguistic variable are determined by the fabricators and the lifting crews, according to their experience and knowledge. The distributions of the membership functions are graphed in Fig. 5. For example, the lifting speed is defined using three fuzzy sets, i.e., slow, medium, and fast. These membership functions are used in the fuzzifier component to calculate the degrees of linguistic variables. Each input factor is explained as follows.

\section{- Lifting speed}

This factor is defined as the time needed to crane up a precast element. On a construction site, the lifting speed is limited by the types and number of crane towers, as well as the element size and weight of the components (Tong and Tam, 2003). The lifting speed generally decreases in correspondence with the complexity of the structure. Moreover, the size of the crew, the hooking speed, and proficiency in manipulating the equipment all impact the craning speed. The speed also varies with the story. This variable is normalized by lower bound 11 elements per day and upper bound 43 elements per day. The lower and upper bounds are calculated by the averages of previous lifting records. Value of this factor is scored in accordance with the construction crew's observations.

\section{- Site layout}

Since precast components are positioned by crane towers, an inappropriate site layout delays erection progress. The storage location as well as the material supply path influence crane movements (Jang et al., 2007). Moreover, the shape of the building, as well as of nearby projects, the status of traffic, and barriers in the sky all impact erection progress. This variable is scored by subjective recognition ranging from 0 to 1 .

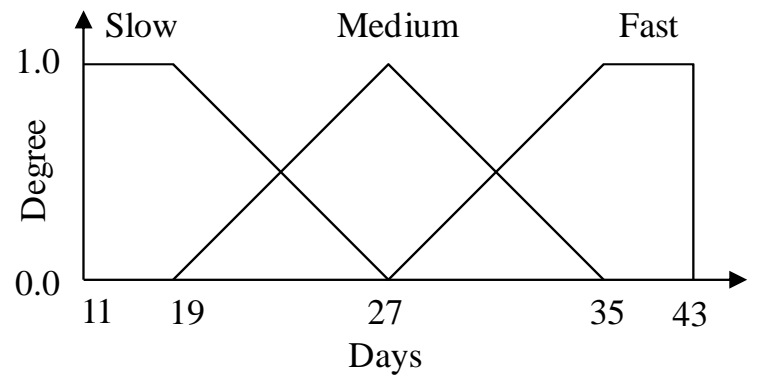

(a)

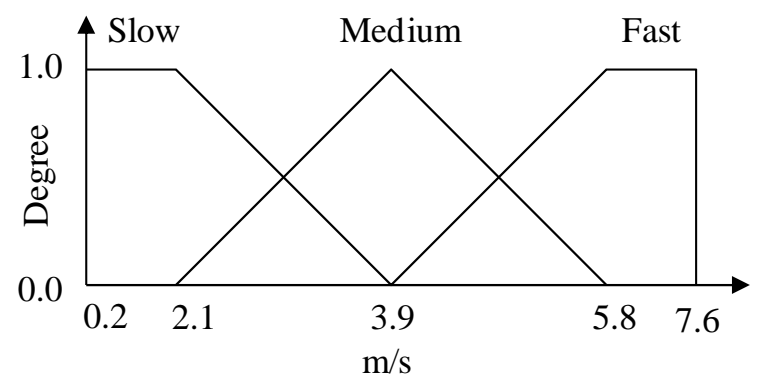

(c)

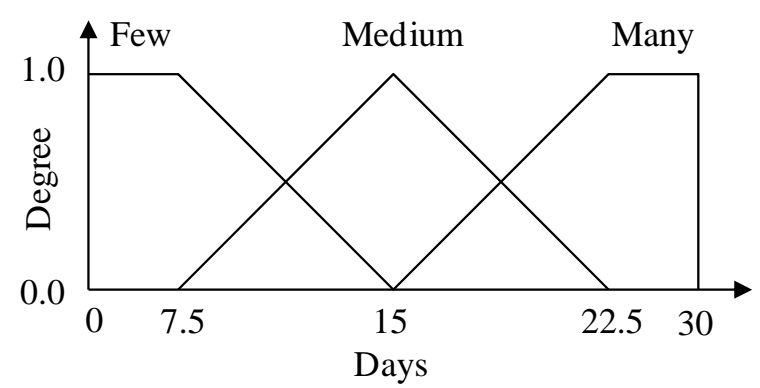

(e)

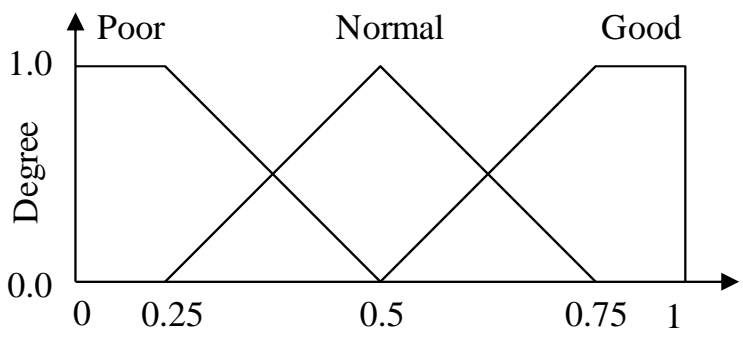

(b)

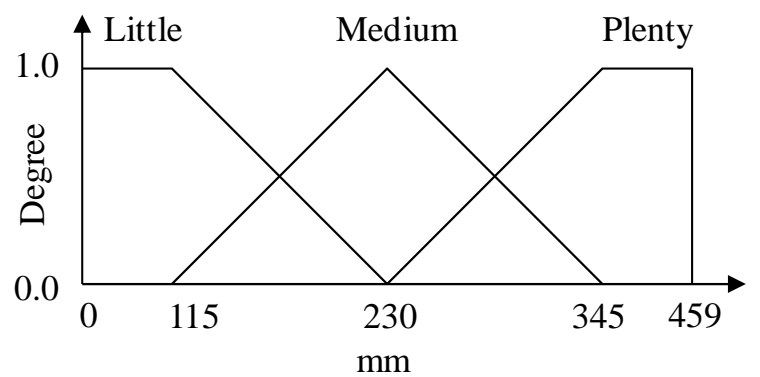

(d)

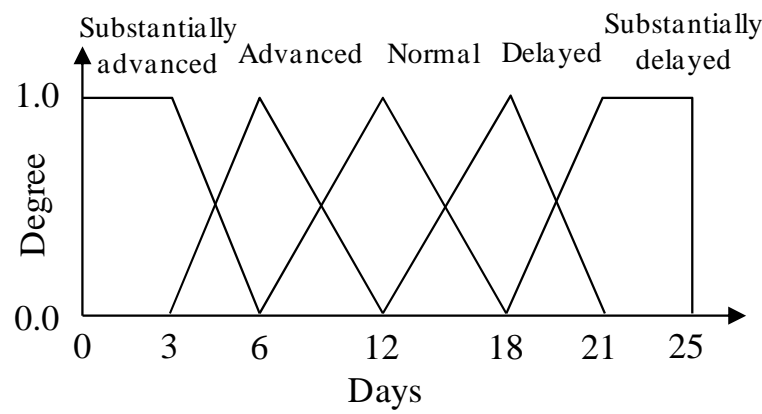

(f)

Fig. 5. Fuzzy sets of input/output variables: (a) Lifting speed (b) Site layout (c) Wind speed (d) Rainfall (e) Consecutive rainy days (f) Erection duration 
- Wind speed

Erection progress is directly associated with wind speed. Side forces enhanced by the wind's swaying of precast components increase difficulties in erection operation (Voisin, 1999). Operating lifting procedures under windy conditions may even create hazardous situations. Wind speed is a seasonable variable, which can be approximated through weather forecasts (Barlow and Tippett, 2005; Kainkwa, 2000). The upper and lower bounds are thus determined using historical wind speeds. The linguistic variable is normalized by the lower bound $0.2(\mathrm{~m} / \mathrm{s})$ and the upper bound $7.6(\mathrm{~m} / \mathrm{s})$, the factor being evaluated in accordance with weather forecasts and historical data.

\section{- Precipitation}

Rain impacts almost all kinds of construction operations (El-Rayes, K. and Moselhi, 2001). Light rain has a minor impact; whereas, heavy rainfall interrupts erection progress. Rainfall depth is also a seasonable variable which can be approximated from weather forecasts (Ali et al., 2000; Chen and Taylor, 2002). The upper and lower bounds are determined using historical data. These variables are normalized by $0(\mathrm{~mm})$ and 459 $(\mathrm{mm})$, respectively. The value of this factor is input in accordance with weather forecasts and historical data.
- Consecutive rainy days

The number of consecutive rainy days plays a key role in evaluating construction duration. If precipitation is concentrated into only a few days, construction cannot proceed; however, the impact is limited if the precipitation is more widely distributed. This variable ranges from 0 to 25 days, approximated according to weather forecasts and historical data.

\section{- Erection duration}

The output of the inference is erection duration which considers the aforementioned factors. Five fuzzy sets are used to define this variable, the universe of discourse being between 0 and 25 days.

\section{Establish fuzzy rules}

To formulate rules representing a practical status, fuzzy rules are established on the basis of facts or human knowledge (Zadeh, 1973). Fuzzy rules can generally be generated by one of the following methods: 1) the manipulator's behavior, 2) expert knowledge and experience, and 3) characteristics of the inference systems. This study establishes 32 fuzzy rules by interviewing experts, as shown in Table 1.

Table 1. Fuzzy rule base

\begin{tabular}{|c|c|}
\hline Number & Fuzzy rule \\
\hline 1 & $\begin{array}{l}\text { IF (Wind speed is Slow AND Site layout is Good AND Lifting speed is Fast) } \\
\text { THEN (Progress is Substantially advanced) }\end{array}$ \\
\hline 2 & $\begin{array}{l}\text { IF (Wind speed is Slow AND Site layout is Good AND Lifting speed is Medium) } \\
\text { THEN (Progress is Advanced) }\end{array}$ \\
\hline 3 & $\begin{array}{l}\text { IF (Wind speed is Slow AND Site layout is Normal AND Lifting speed is Fast) } \\
\text { THEN (Progress is Advanced) }\end{array}$ \\
\hline 4 & $\begin{array}{l}\text { IF (Wind speed is Slow AND Site layout is Good AND Lifting speed is Slow) } \\
\text { THEN (Progress is Normal) }\end{array}$ \\
\hline 5 & $\begin{array}{l}\text { IF (Wind speed is Slow AND Site layout is Poor AND Lifting speed is Fast) } \\
\text { THEN (Progress is Normal) }\end{array}$ \\
\hline 6 & $\begin{array}{l}\text { IF (Wind speed is Slow AND Site layout is Poor AND Lifting speed is Medium) } \\
\text { THEN (Progress is Delayed) }\end{array}$ \\
\hline 7 & $\begin{array}{l}\text { IF (Wind speed is Slow AND Site layout is Normal AND Lifting speed is Slow) } \\
\text { THEN (Progress is Delayed) }\end{array}$ \\
\hline 8 & $\begin{array}{l}\text { IF (Wind speed is Slow AND Site layout is Poor AND Lifting speed is Slow) } \\
\text { THEN (Progress is Delayed) }\end{array}$ \\
\hline 9 & $\begin{array}{l}\text { IF (Wind speed is Medium AND Site layout is Good AND Lifting speed is Fast) } \\
\text { THEN (Progress is Advanced) }\end{array}$ \\
\hline 10 & $\begin{array}{l}\text { IF (Wind speed is Medium AND Site layout is Good AND Lifting speed is Normal) } \\
\text { THEN (Progress is Normal) }\end{array}$ \\
\hline 11 & $\begin{array}{l}\text { IF (Wind speed is Medium AND Site layout is Normal AND Lifting speed is Fast) } \\
\text { THEN (Progress is Normal) }\end{array}$ \\
\hline 12 & $\begin{array}{l}\text { IF (Wind speed is Medium AND Site layout is Good AND Lifting speed is Slow) } \\
\text { THEN (Progress is Delayed) }\end{array}$ \\
\hline 13 & $\begin{array}{l}\text { IF (Wind speed is Medium AND Site layout is Poor AND Lifting speed is Fast) } \\
\text { THEN (Progress is Delayed) }\end{array}$ \\
\hline
\end{tabular}


Table 1. Fuzzy rule base (continued)

\begin{tabular}{|c|c|}
\hline Number & Fuzzy rule \\
\hline 14 & $\begin{array}{l}\text { IF (Wind speed is Medium AND Site layout is Poor AND Lifting speed is Normal) } \\
\text { THEN (Progress is Substantially delayed) }\end{array}$ \\
\hline 15 & $\begin{array}{l}\text { IF (Wind speed is Medium AND Site layout is Normal AND Lifting speed is Slow } \\
\text { THEN (Progress is Substantially delayed) }\end{array}$ \\
\hline 16 & $\begin{array}{l}\text { IF (Wind speed is Medium AND Site layout is Poor AND Lifting speed is Slow) } \\
\text { THEN (Progress is Substantially delayed) }\end{array}$ \\
\hline 17 & $\begin{array}{l}\text { IF (Wind speed is Fast) } \\
\text { THEN (Progress is Substantially delayed) }\end{array}$ \\
\hline 18 & $\begin{array}{l}\text { IF (Rainfall is Less AND Raining days is Few AND Site layout is Good AND Lifting speed is } \\
\text { Fast) } \\
\text { THEN (Progress is Substantially advanced) }\end{array}$ \\
\hline 19 & $\begin{array}{l}\text { IF (Precipitation is Little AND Rainy days are Few AND Site layout is Good AND Lifting speed } \\
\text { is Medium) } \\
\text { THEN (Progress is advanced) }\end{array}$ \\
\hline 20 & $\begin{array}{l}\text { IF (Precipitation is Little AND Rainy days are Few AND Site layout is Normal AND Lifting } \\
\text { speed is Fast) } \\
\text { THEN (Progress is advanced) }\end{array}$ \\
\hline 21 & $\begin{array}{l}\text { IF (Precipitation is Little AND Rainy days are Few AND Site layout is Good AND Lifting speed } \\
\text { is Slow) } \\
\text { THEN (Progress is Normal) }\end{array}$ \\
\hline 22 & $\begin{array}{l}\text { IF (Precipitation is Little AND Rainy days are Few AND Site layout is Poor AND Lifting speed } \\
\text { is Fast) } \\
\text { THEN (Progress is Normal) }\end{array}$ \\
\hline 23 & $\begin{array}{l}\text { IF (Precipitation is Little AND Rainy days are Few AND Site layout is Poor AND Lifting speed } \\
\text { is Medium) } \\
\text { THEN (Progress is Delayed) }\end{array}$ \\
\hline 24 & $\begin{array}{l}\text { IF (Precipitation is Little AND Rainy days are Few AND Site layout is Normal AND Lifting } \\
\text { speed is Slow) } \\
\text { THEN (Progress is Delayed) }\end{array}$ \\
\hline 25 & $\begin{array}{l}\text { IF (Precipitation is Little AND Rainy days are Few AND Site layout is Poor AND Lifting speed } \\
\text { is Slow) } \\
\text { THEN (Progress is Delayed) }\end{array}$ \\
\hline 26 & $\begin{array}{l}\text { IF (Precipitation is Little AND Rainy days are Many) } \\
\text { THEN (Progress is Normal) }\end{array}$ \\
\hline 27 & $\begin{array}{l}\text { IF (Precipitation is Plenty AND Rainy days are Few) } \\
\text { THEN (Progress is Delayed) }\end{array}$ \\
\hline 28 & $\begin{array}{l}\text { IF (Precipitation is Plenty AND Rainy days are Medium) } \\
\text { THEN (Progress is Substantially delayed) }\end{array}$ \\
\hline 29 & $\begin{array}{l}\text { IF (Precipitation is Plenty AND Rainy days are Many) } \\
\text { THEN (Progress is Substantially delayed) }\end{array}$ \\
\hline 30 & $\begin{array}{l}\text { IF (Precipitation is Medium AND Rainy days are Few) } \\
\text { THEN (Progress is Delayed) }\end{array}$ \\
\hline 31 & $\begin{array}{l}\text { IF (Precipitation is Medium AND Rainy days are Medium) } \\
\text { THEN (Progress is Substantially delayed) }\end{array}$ \\
\hline 32 & $\begin{array}{l}\text { IF (Precipitation is Medium AND Rainy days are Many) } \\
\text { THEN (Progress is Delayed) }\end{array}$ \\
\hline
\end{tabular}




\section{Determine Defuzzification Method}

The centroid technique is one of the most popular methods used for defuzzification. This study thus adopts Center Of Gravity (COG) as a defuzzification method. Theoretically, the COG is calculated over a continuum of points in the aggregate output membership function. However, a reasonable approximation can be obtained by calculating it over a sampling of points (Negnevitsky, 2005). The COG method is formulated by Eq. (1), as graphed in Fig. 6.

$$
C O G=\frac{\sum_{x=a}^{b} \mu_{A}(x) x}{\sum_{x=a}^{b} \mu_{A}(x)}
$$

\subsection{Time Buffer Adjustment}

Erection duration is approximated by using the fuzzy logic addressed in previous sections. According to the estimated duration, the production due dates can be analyzed. The goal of the precast fabricator is to deliver components to the building site according to the progress in construction. To achieve this goal, a contingency time buffer is required. However, too much buffer induces wasteful accumulation of inventory; whereas, too little risks a loss in fabrication capacity. The objective of this study is to evaluate a time buffer that provides an appropriate time cushion with less inventory. The proposed method examines the tardiness penalty and crashing cost by considering the late delivery scenarios established in this study. The cost of the tardiness penalty for component $\left(C_{t e}\right)$ of a story can be formulated as Eq. (2).

$$
C_{t e}=\left(\frac{D_{i} \times C_{t d}}{N_{e}}\right)
$$

where $D_{i}$ represents the erection duration for the story, inferred using FL; $C_{t d}$, the cost of the tardiness penalty per day; and $N_{e}$, the number of components in the story. The crashing cost for a component $\left(C_{c e}\right)$, denoted in Eq. (3), includes fees accrued to additional working hours, namely water fees $\left(C_{w}\right)$, electricity $\left(C_{e}\right)$, overtime wages $\left(C_{o}\right)$, and material costs induced by shortening the lead time $\left(C_{m}\right)$, calculated as follows:

$$
C_{c e}=C_{w}+C_{e}+C_{o}+C_{m} .
$$

According to Eq. (2), the cost of the tardiness penalty for a component $\left(C_{t e}\right)$ decreases with the number of components $\left(N_{e}\right)$; whereas, the crashing cost for a component $\left(C_{c e}\right)$ increases with the number of components required for overtime work. Fig. 7 graphs the trends in the curves. In this research, the intersection of the tardiness penalty and the crashing cost curves is defined as the production break-even point $\left(N_{b e}\right)$. Prior to this point, the crashing cost is less expensive than the tardiness penalty, meaning that once the fabricator becomes aware of failure to fulfill the erection schedule, overtime work should be immediately launched since overtime is more economical than the tardiness penalty. After the break-even point, overtime work is still necessary, but the crashing cost is greater than the tardiness penalty. The more the fabricator works, the more losses are incurred.

According to the aforementioned late-delivery scenario, the less expensive the crashing cost, the shorter the required time buffer. This research treats number of components between the break-even point $\left(N_{b e}\right)$ and the components of the story $\left(N_{e}\right)$ as security inventory, denoted as $i$ in Fig. 2. This inventory can be converted into a time buffer, $b_{t}$ in Fig. 2, by dividing throughput $(t p)$. The time buffer is expressed as

$$
b_{t}=\frac{i}{t p} .
$$

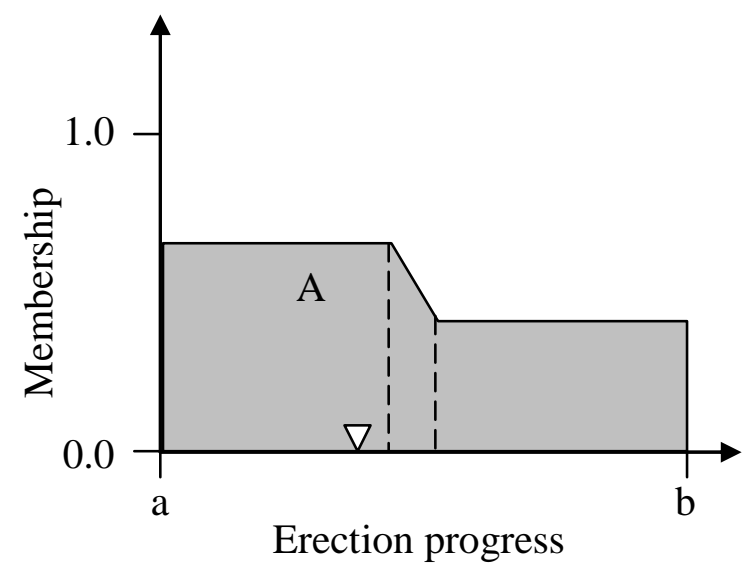

Fig. 6. Center Of Gravity (COG) method 


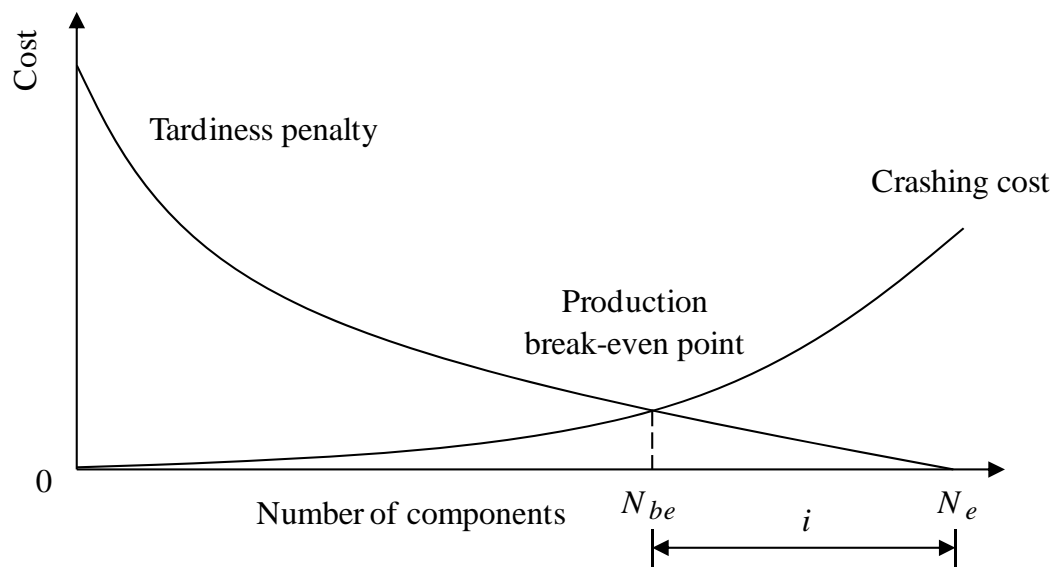

Fig. 7. Comparison of crashing cost and tardiness penalty

Table 2. Required precast components

\begin{tabular}{cccc}
\hline Story & Columns & Major beams & Minor beams \\
\hline B1F & 0 & 195 & 290 \\
1F & 51 & 31 & 7 \\
M1F & 35 & 120 & 165 \\
2F & 72 & 113 & 143 \\
3F & 72 & 118 & 158 \\
$4 F$ & 72 & 122 & 179 \\
RF & 15 & 13 & 17 \\
\hline
\end{tabular}

Table 3. Inputs of erection progress inference

\begin{tabular}{cccccc}
\hline Story & $\begin{array}{c}\text { Erection speed } \\
\text { (components/day) }\end{array}$ & Rainfall(mm) & Rainy days & Wind speed(m/s) & Site layout \\
\hline B1F & 27 & 360 & 15 & 2.9 & 0.6 \\
1F & 25 & 50 & 7 & 2.1 & 0.7 \\
M1F & 32 & 100 & 16 & 2.5 & 0.7 \\
2F & 41 & 113 & 6 & 2.3 & 0.8 \\
3F & 43 & 77 & 13 & 2.2 & 0.8 \\
4F & 29 & 167 & 24 & 2.1 & 0.8 \\
RF & 34 & 62 & 18 & 2.2 & 0.6 \\
\hline
\end{tabular}

\section{Experiment}

An actual Taiwanese case, a furniture mall constructed from precast components, is used to demonstrate the performance of the proposed model. This four-story, one-basement shopping mall has a construction budget of US\$ 5.7 million. The precast components required for each story are listed in Table 2, which indicates that B1F has 195 major and 290 minor beams but no precast column. The mall also has a mezzanine, denoted as M1F, between the first and the second floors.

\subsection{Erection Progress Inference}

The possible erection progress on each story is inferred using FL. The inputs for each story in the developed fuzzy system are listed in Table 3; the inference results, in Table
4. A possible erection schedule for each story is calculated from RF to B1F.

\subsection{Time Buffer Adjustment}

In this study, the time buffer is evaluated by considering the tardiness penalty and the crashing cost. The cost of the tardiness penalty for a component $\left(C_{t e}\right)$ can be derived using Eq. (2). For example, the inferred erection duration $\left(D_{i}\right)$ for B1F is 21 days. The tardiness penalty is one thousandth of the construction budget for the project, i.e., US\$5667 per day $\left(C_{t d}\right)$. The total tardiness penalty for the $\mathrm{B} 1 \mathrm{~F}$ is US $\$ 119000$. By dividing this total by 485 components, the per-component penalty $\left(C_{t e}\right)$, i.e. US $\$ 245$, can be calculated. The tardiness penalties for each story are listed in Table 5. 
Table 4. Inference results

\begin{tabular}{ccc}
\hline Story & Inferred erection duration & Inferred production due date \\
\hline B1F & 21 & $9 / 15$ \\
1F & 15 & $9 / 19$ \\
M1F & 12 & $10 / 5$ \\
2F & 8 & $10 / 19$ \\
3F & 8 & $11 / 5$ \\
4F & 14 & $11 / 21$ \\
RF & 11 & $12 / 6$ \\
\hline
\end{tabular}

Table 5. Tardiness penalty for each story

\begin{tabular}{cc}
\hline Story & Tardiness penalty per component $\left(C_{t e}\right)$ \\
\hline B1F & 245 \\
$1 \mathrm{~F}$ & 382 \\
M1F & 142 \\
$2 \mathrm{~F}$ & 104 \\
$3 \mathrm{~F}$ & 147 \\
$4 \mathrm{~F}$ & 182 \\
$\mathrm{RF}$ & 881 \\
\hline
\end{tabular}

Table 6. Time buffer for each story

\begin{tabular}{cccc}
\hline Story & Production break-even point & Time buffer & Buffered production due dates \\
\hline B1F & 428 & 3 & $9 / 12-9 / 15$ \\
1F & 66 & 2 & $9 / 17-9 / 19$ \\
M1F & 263 & 3 & $10 / 2-10 / 5$ \\
2F & 205 & 5 & $10 / 14-10 / 19$ \\
3F & 253 & 4 & $11 / 1-11 / 5$ \\
4F & 286 & 5 & $11 / 16-11 / 21$ \\
RF & 43 & 1 & $12 / 5-12 / 6$ \\
\hline
\end{tabular}

The precast components are assembled in sequence, i.e., columns, then major and minor beams. In a crash, the production and construction sequences correspond. The crashing cost can be evaluated by the weight of components. Among these, the column is the heaviest followed by the major and minor beams. The throughput of the studied factory is about 20 components per day. the number of steel molds for the columns and the major and minor beams are 6,16 , and 20 , respectively. When using $\mathrm{B} 1 \mathrm{~F}$ as an example, at the beginning the crash, the factory primarily fabricates major beams since $\mathrm{B} 1 \mathrm{~F}$ has no column. In one weekday, the factory can fabricate 16 major and 4 minor beams. The 195 major and 52 minor beams require 13 production days (totaling 260 components). Afterward, the factory primarily fabricates minor beams having lighter weights and lower crashing costs. The total weights of the major and minor beams are 2015 and 1077 tons, respectively. Moreover, crashing cost is US\$7 per ton. Hence, the crashing cost is US\$52 per component if production does not exceed 260 components; whereas, this cost falls to US\$32 per component when production exceeds 260.

The production break-even point defined in this study can be obtained by calculating the intersection of the tardiness penalty and crashing cost curves. The break-even points for each story are listed in Table 6. A time buffer can be determined by dividing the break-even point by the throughput. For example, the break-even point for B1F is 428 components $\left(N_{b e}=428\right)$; the components in the story, is $485\left(N_{e}=485\right)$; the security inventory, $57(i=(485-428)=57)$; and the throughput of the factory, 20 components per day $(t p)$. A three-day time buffer $\left(b_{t}=3\right)$ for B1F can be obtained by applying Eq. (4). 
Table 7. Comparisons of actual and adjusted production data

\begin{tabular}{ccccc}
\hline Story & Completion day & $\begin{array}{c}\text { Adjusted production } \\
\text { components }\end{array}$ & $\begin{array}{c}\text { Actual production } \\
\text { components }\end{array}$ & $\begin{array}{c}\text { Reduced } \\
\text { inventory }\end{array}$ \\
\hline B1F & $9 / 12$ & 485 & 1099 & $56 \%$ \\
1F & $9 / 17$ & 574 & 1208 & $52 \%$ \\
M1F & $10 / 2$ & 894 & 1491 & $40 \%$ \\
2F & $10 / 14$ & 1222 & 1660 & $26 \%$ \\
3F & $11 / 1$ & 1570 & 1891 & $17 \%$ \\
$4 F$ & $11 / 16$ & 1943 & 1978 & $1.8 \%$ \\
RF & $12 / 5$ & 1988 & 1988 & 0 \\
\hline
\end{tabular}

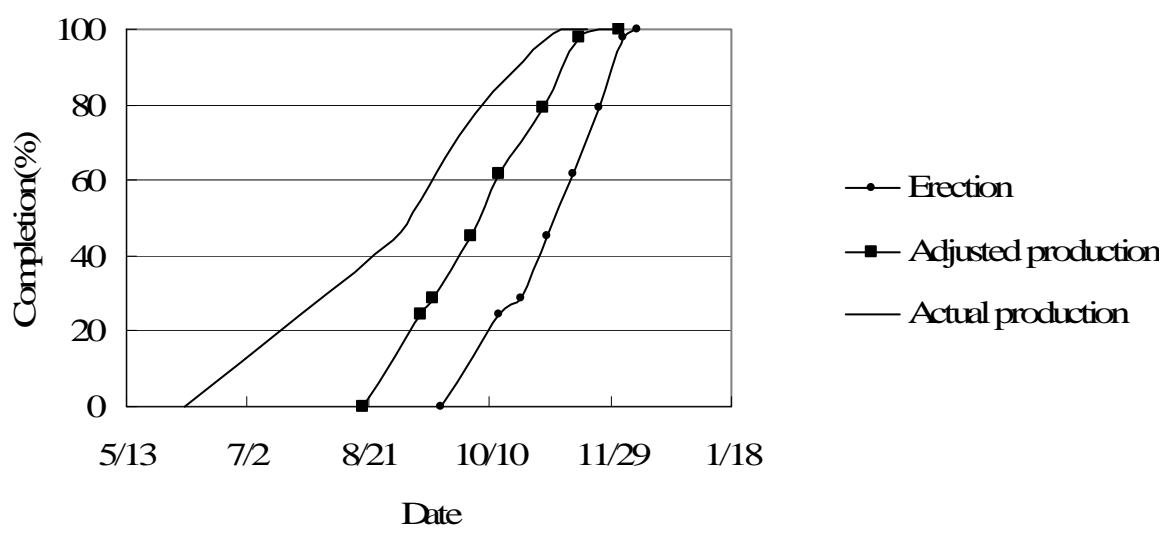

Fig. 8. Comparisons of production curves

\subsection{Discussion}

Table 7 lists comparisons of both the actual and the adjusted production data. The erection, actual-production, and adjusted-production curves are graphically illustrated in Fig. 8. According to this figure, the proposed method for finishing production later relative to delivery dates by means of a time buffer is closer to the progress of the erection. Hence, the level of finished goods inventory can be decreased. Moreover, the possibility of the fabricator's succumbing to the impact of variability can be reduced.

\section{Conclusions}

This report has elucidated the research on the development of the Time Buffer Evaluation Model (TBEM) to deliver products on time while accumulating less inventory. This model consists of two stages, i.e., erection duration inference and time buffer adjustment. The erection duration was inferred using FL; whereas, the time buffer was adjusted by considering the tardiness penalty and the crashing cost.

This study adopted a production strategy that finishes production later relative to delivery dates to reduce both inventory and the impact of demand variability. To avoid out-of-capacity fabrication due to a late production, this paper analyzed a time buffer from a pessimistic perspective in a crashing scenario. The experiment results showed that by adopting the proposed model, the level of finished goods inventory can be reduced without changing the production resources. Fabricators can thus reduce the risks of changes in delivery dates and manufacturing a product that is either not yet needed or succumbs to design changes. The proposed TBEM can be further enhanced in the future by carrying out more theoretical and empirical investigations.

\section{Acknowledgements}

This research was funded by grant NSC 94-2218-E-212-011 from the National Science Council, Taiwan, whose support is gratefully acknowledged. Any opinions, findings, conclusions, or recommendations expressed in the paper are those of the authors and do not necessarily reflect the views of the National Science Council. The authors would also like to thank the investigated precast fabricator for supporting this study. Appreciation is also expressed to Dr. Cheryl Rutledge for her editorial assistance.

\section{References}

Adenso-Diaz, B., Gonzalez, I., and Tuya, J. (2004). Incorporating fuzzy approaches for production planning in complex industrial environments: The roll shop case. Engineering Applications of Artificial Intelligence, 17(1), 73-81.

Ali, A., Abtew, W., Van Horn, S., and Khanal, N. (2000). Temporal and spatial characterization of rainfall over Central and South Florida. Journal of the American Water Resources Association, 36(4), 833-848.

Ballard, G. and Arbulu, R. (2004). Taking prefabrication lean. Proceedings of the 12th Annual Conference of 
the International Group for Lean Construction, Elsinore, Denmark.

Barlow, M., and Tippett, M. (2005). Predicting Central Asian river flows from regional precipitation and wind patterns during the preceding cold season. IAHS-AISH Publication, 296, 221-227.

Chang, S. C. (1999). Fuzzy production inventory for fuzzy product quantity with triangular fuzzy number. Fuzzy Sets and Systems, 107(1), 37-57.

Chen, A. A., and Taylor, M. A. (2002). Investigating the link between early season Caribbean rainfall and the El Nino+1 year. International Journal of Climatology, 22(1), 87-106.

Didier, D., Henri, P., and James, C. B. (2007). Fuzzy sets in approximate reasoning and information systems. Kluwer Academic Publisher, Norwell, Massachusetts.

El-Rayes, K. and Moselhi, O. (2001). Impact of rainfall on the productivity of highway construction. Journal of Construction Engineering and Management, 127(2), $125-131$.

Hopp, W. J., and Spearman M. L. (2000). Factory Physics: Foundations of Manufacturing Management, 2nd Edition. McGraw-Hill, NY, NY.

Jang, H., Lee, S., and Choi, S. (2007). Optimization of floor-level construction material layout using genetic algorithms. Automation in Construction, 16(4), 531-545.

Kainkwa, R. M. R. (2000). Wind speed pattern and the available wind power at Basotu, Tanzania. Renewable Energy, 21(2), 289-295.

Ko, C. H. and Ballard, G. (2004). Demand variability and fabrication lead time: Descriptive research, phase $I$. Technical Report, University of California at Berkeley, Berkeley, CA.

Ko, C. H. and Ballard, G. (2005). Fabrication lead time and demand variability: An empirical study. Proceedings of the Construction Research Congress, American Society of Civil Engineers, San Diego, CA, 17-21.

Mamdani, E. H. and Assilian, S. (1975). An experiment in linguistic synthesis with a fuzzy logic controller. International Journal of Man-Machine Studies, 7(1), 1-13.

Negnevitsky, M. (2005). Artificial intelligence: A guide to intelligent systems, 2nd Edition, Addison-Wesley, Harlow, England.

Ohno, T. (1988). Toyota Production System: Beyond Large-Scale Production. Cambridge, MA.

Riley, D. R., Diller, B. E., Kerr, D. (2005). Effects of delivery systems on change order size and frequency in mechanical construction. Journal of Construction Engineering and Management, 131(9), 953-962.

Singh, R. K., Kumar, S., Choudhury, A. K., and Tiwari, M. K. (2006). Lean tool selection in a die casting unit: A fuzzy-based decision support heuristic. International Journal of Production Research, 44(7), 1399-1429.

Spearman, M. L. (2002). To pull or not to pull, what is the question? Part ii: Making lean work in your plant. White Paper Series, Factory Physics, Inc., 1-7.

Tong, T. K. L. and Tam, C. M. (2003). GA-ANN model for optimizing the locations of tower crane and supply points for high-rise public housing construction. Construction Management and Economics, 21(3), 257-266.

Voisin, D., Grillaud, G.., Solliec, C., Beley-Sayettat, A., Berlaud, J. L., and Miton, A. (2004). Wind tunnel test method to study out-of-service tower crane behaviour in storm winds. Journal of Wind Engineering and Industrial Aerodynamics, 92(8), 687-697.

Wang, W., Wang, D., and Ip, W. H. (1999). JIT production planning approach with fuzzy due date for OKP manufacturing systems. International Journal of Production Economics, 58, 209-215.

Zadeh, L. A. (1965). Fuzzy sets. Information and Control, 8, 338-353.

Zadeh, L. A. (1973). Outline of a new approach to the analysis of complex systems and decision processes. IEEE Transactions on Systems, Man, and Cybernetics, 3(1), 28-44.

Zadeh, L. A. (1994). Soft computing and fuzzy logic. IEEE Software, 48-56.

Zadeh, L. A. (2005). From search engines to question-answering systems - The role of fuzzy logic. Progress in Informatics, 1, 1-3.

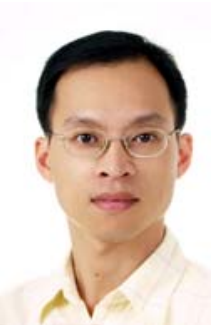

Dr. Chien-Ho Ko is currently an associate professor in the Civil Engineering Department at National Pingtung University of Science and Technology. He was a faculty member in the Industrial Engineering and Technology Management Department at Da-Yeh University. Prior to this profession, Dr. Ko conducted his postdoctoral research at the University of California at Berkeley, sponsored by government funds of Ministry of Education. He is a registered professional engineer of fire protection. His research encompasses around project production management, robotics, artificial intelligence, and fire protection.

Yu-Chun Chen received Master of Science at Da-Yeh University, Taiwan. His research interests are applications of fuzzy logic in industrial engineering and technology management. 